\title{
Espaço Aberto
}

\section{Áreas e subáreas do conhecimento, vínculos epistemológicos: o GT de Educação Matemática da ANPEd*}

\author{
Antonio Miguel \\ Universidade Estadual de Campinas, Faculdade de Educação
}

O problema de fundo, mais geral, que constitui meu objeto de investigação e reflexão apresenta-se claramente definido pelo título deste artigo. Com base nele, discutiremos o caso específico do GT de Educação Matemática, que integra o conjunto dos GTs da ANPEd.

O problema de fundo a que nos referimos comporta pelo menos dois aspectos. Um deles diz respeito à compartimentalização do saber em áreas e subáreas, com base em critérios epistemológicos diferenciadores. O outro se refere à identificação de vínculos entre áreas ou subáreas já estabelecidas do saber, com base em critérios de afinidade epistemológica.

É claro que não fomos os primeiros a investigar um problema dessa natureza. Desde a emergência das primeiras propostas de classificação das ciências, ainda na Antigüidade, até o momento em que tais propostas atingem seu apogeu, durante o século XIX,

"Este texto, com pequenas alterações adaptativas, foi apresentado no Grupo de Trabalho (GT) de Educação Matemática, na $29^{\text {a }}$ Reunião Anual da Associação Nacional de Pós-Graduação e Pesquisa em Educação (ANPEd), realizada em Caxambu (MG) de 15 a 18 de outubro de 2006. com o advento, entre outros, de dois influentes sistemas de classificação - o de Comte e o de Engels ${ }^{1}$-, esse debate parece ter-se baseado no pressuposto otimista da necessidade e relevância da produção de projetos universais de classificação do conhecimen-

${ }^{1} \mathrm{O}$ sistema de classificação das ciências proposto por Augusto Comte, no seu Curso de filosofia positiva, publicado no final da primeira metade do século XIX, foi fortemente inspirado nas idéias de Saint-Simon e tomava como critério de partida a relação hierárquica de dependência que poderia ser estabelecida entre os diferentes tipos de fenômenos do mundo exterior. Com base nesse critério e segundo uma relação de caráter especular, os diferentes domínios da ciência correspondentes a cada um desses tipos de fenômenos deveriam ser igualmente hierarquizados. Friedrich Engels, em uma carta de 30 de maio de 1873 dirigida a Karl Marx, sugeriu a idéia de que as diferentes ciências naturais poderiam ser diferenciadas - e, portanto, classificadas - segundo o critério dialético das diferentes formas de movimento presentes na natureza que cada uma delas tomaria como objeto de investigação. Essa idéia foi posteriormente desenvolvida no seu A dialética da natureza. Um estudo detalhado dessas e de outras propostas de classificação das ciências pode ser encontrado em Kedrov (1974). 
to. Divergências ocorriam. Porém, parecia que elas se restringiam à natureza e justificação dos critérios subjacentes a tais classificações, com base em tal ou qual teoria ou filosofia.

Entretanto, a partir da segunda metade do século $\mathrm{XX}$, esse debate sofre uma guinada crítica e cética. Entre os mais moderados, essa virada caracterizou-se pela desconfiança em relação a qualquer tipo de $\mathrm{em}$ preendimento universal e absolutista de classificação do saber, sobretudo em relação àqueles projetos baseados em teorias evolucionistas e etapistas do processo de produção de conhecimento, fossem tais teorias orientadas por um evolucionismo linear - como a de Comte - ou por um evolucionismo dialético - como a de Engels. Entre os mais radicais, essa desconfiança, que assumiu o tom cético de recusa a qualquer empreendimento universal e absolutista de compartimentalização do saber, veio acompanhada da defesa de um empreendimento, igualmente universal e absolutista, de afirmação da unidade do saber.

Edgar Morin poderia ser aqui invocado como um dos pensadores contemporâneos que têm manifestado o que chamamos temor epistemológico relativo à compartimentalização. Um tal temor seria algo análogo àquilo que Georges Gusdorf chamou de patologia do saber e que Morin denomina novo obscurantismo. Segundo Morin, o novo obscurantismo seria um fenômeno derivado da fragmentação do saber, com sérias implicações negativas em razão do fato de ele destruir a possibilidade de produzir um conhecimento do conhecimento, um conhecimento de nós mesmos e um conhecimento do mundo (Morin, 1999, p. 22-23).

Sinceramente, não vejo razões para responsabilizar o fenômeno da fragmentação e especialização do saber pela nossa suposta incapacidade de produzir um conhecimento do conhecimento, um conhecimento de nós mesmos e do mundo. Ao contrário, foi exatamente a partir do final do século XVIII - momento em que a fragmentação e a especialização do saber começaram a tornar-se cada vez mais irreversivelmente intensas - que assistimos também ao nascimento de campos de conhecimentos autônomos, específicos e especializados, como a teoria do conhecimento, a psicanálise, a sociologia, a antropologia, a cosmologia etc., produzindo cada vez mais, e mais profundamente, conhecimentos sobre a natureza, sobre o homem, sobre a sociedade e sobre o próprio conhecimento.

"Inconscientes do que é e faz a ciência na sociedade", afirma Morin (1999, p. 23), "os cientistas são incapazes de controlar os poderes escravizadores ou destrutores gerados pelo saber". E essa seria, segundo ele, outra implicação negativa da fragmentação do saber. Tendemos a concordar com Morin em que, muitas vezes, os cientistas não são capazes de controlar não apenas os poderes destrutivos mas também os construtivos dos saberes que produzem; porém, em muitas situações, essas variáveis não somente são previsíveis, como também perfeitamente controláveis. Mas nossa principal objeção a esse argumento de Morin é que o controle dos usos sociais do conhecimento não é uma tarefa exclusiva do cientista individual, ou mesmo da comunidade científica, mas de todo cidadão, cabendo, portanto, à sociedade civil, devidamente organizada em suas instituições sociais e políticas, realizar tal controle.

Outro exemplo foi a polêmica que se travou em 1998 entre o filósofo pragmático norte-americano Richard Rorty e o biólogo também norte-americano Edward O. Wilson acerca do livro publicado por este último com o sugestivo título Consiliência: a unidade do conhecimento.

Segundo o próprio Wilson, o filósofo William Whewell teria sido o primeiro a utilizar a palavra consiliência, em uma obra de 1840 denominada $A$ filosofia das ciências indutivas, para significar, literalmente, "um salto qualitativo do conhecimento devido ao estabelecimento de ligação entre os fatos de todas as disciplinas, a fim de criar uma base comum de explicação, [sendo a consiliência] a chave para a unificação".

A tese principal dessa obra de Wilson é de que seria

\footnotetext{
[...] um erro pensar que existem inúmeros tipos de explica-

ções apropriadas às perspectivas das disciplinas individuais, pois existe, intrinsecamente, apenas uma classe de explicação que atravessa as escalas de tempo e de complexidade
} 
para unir os fatos díspares das disciplinas por meio da concordância, da percepção de uma rede inconsútil de causas e efeitos. (Wilson, apud Rorty, 1998, p. 7; Wilson, 1999, p. 257)

Note-se o emprego da sugestiva palavra inconsútil, que significa "sem costura, sem emendas, feito de uma só peça”.

Vamos atentar agora para o contra-argumento de Richard Rorty a essa inconsútil e, a nosso ver, pouco sutil tese de Wilson.

Por que uma rede inconsútil de causas e efeitos acarretaria a possibilidade ou a desejabilidade de uma rede explicativa também inconsútil? Para nós, pragmatistas, pode e deve haver milhares de formas de descrever as coisas e as pessoas - tantas quantos forem os propósitos que tivermos em relação às coisas e às pessoas. Mas essa pluralidade não é problemática, não suscita problemas filosóficos e nem fragmenta o conhecimento. As disciplinas acadêmicas não são e nem devem ser reflexos do mundo real. Devem, sim, propiciar as maneiras de fazer as coisas no mundo real, de tecer a grande rede inconsútil das causas, de modo que os objetivos humanos sejam alcançados. A realidade é uma, mas as descrições dela são incontáveis [...], porque os seres humanos têm e devem ter objetivos diversos. Não devemos arrancar os cabelos por nossa infortunada cultura desunida. Não devemos eliminar as barreiras entre as disciplinas. Aliás, duvido da existência dessas barreiras. (Rorty, 1998, p. 7-8)

Como podemos observar, o argumento epistemológico de Rorty contra a tese da unidade do saber de Wilson, embora pareça admitir a hipótese holística no funcionamento da natureza e da sociedade, não admite que tal hipótese nos obrigue a fornecer também explicações holísticas do funcionamento da natureza e da sociedade. Mais do que isso: segundo ele, a um holismo unitário e articulador da natureza e da sociedade corresponderia uma compartimentalização explicativa, pluralista e igualmente articuladora das disciplinas acadêmicas. E o critério propriamente pragmático que Rorty levanta para justificar esse seu argumento epistemológico contrário à unidade do saber é o da natureza diversa e plural dos propósitos humanos.

Embora concorde com esse argumento antiespecular de Rorty, não tendo a compartilhar da justificativa exclusivamente pragmática que o sustenta. Em outras palavras, penso que, embora os propósitos humanos condicionem a natureza das explicações pluralistas da natureza e da sociedade, eles não têm o poder, por si sós - sem enfrentar resistências muitas vezes imperativas e impeditivas, tanto por parte da natureza quanto por parte das situações sociais - de determinar a natureza das explicações pluralistas nem as compartimentalizações diversas que o saber assume em diferentes situações concretas. Mesmo porque acreditamos que, em qualquer situação concreta, nunca nos deparamos ou tomamos decisões exclusivamente com base em algo assim tão genérico, abstrato e homogêneo como a categoria rortyana "propósitos humanos", mas sim com base em um conjunto heterogêneo, difuso e conflituoso de condicionamentos de natureza e origem diversas, dentre os quais, é claro, se incluem propósitos, intenções e interesses diferenciados de grupos humanos envolvidos na situação, bem como as relações assimétricas de poder que os envolvem e nas quais eles se envolvem.

Pensamos, então, que a estrutura compartimentalizadora que assume o saber humano no espaço acadêmico é fruto de um conjunto variável de condicionamentos que pode incluir, por exemplo: o projeto político-acadêmico da comunidade de prática científica; o contexto geopolítico de ação de tal comunidade; o estado do conhecimento científico, tecnológico, filosófico e do conhecimento em geral em cada momento; as demandas e pressões políticas, econômicas, sociais e profissionais que imperam sobre a comunidade de prática científica em cada momento; o estado das instituições científicas, das instituições definidoras de políticas científicas, dos recursos tecnológicos e dos investimentos científicos; as relações institucionais de poder que envolvem os membros da comunidade de prática científica, bem como aquelas que se estabelecem entre essa e outras comunidades etc. 
Acredito, portanto, não fazer mais sentido continuar a refletir sobre o problema da compartimentalização do saber de forma genérica, universal e abstrata, uma vez que tal problema não constitui um problema para todas as comunidades de prática e mesmo para aquelas comunidades que o constituem como um problema para si próprias ele não se apresenta, ao longo do tempo e das circunstâncias situacionais, do mesmo modo nem com a mesma intensidade, nem pode ser abordado de maneira uniforme que conduza a soluções definitivas generalizáveis.

Em decorrência disso, pensamos que, em nossos dias, a discussão relativa ao problema epistemológico da compartimentalização do saber em áreas e subáreas bem demarcadas e do estabelecimento de possíveis vínculos entre elas com base em critérios epistemológicos explícitos deveria vir conectada à discussão do problema transepistemológico que se indaga acerca das razões pelas quais, e em que sentido, para certas comunidades de práticas situadas um tal problema constituiria de fato um problema; e, em se tratando realmente de um problema, em que medida ele poderia, ou mesmo deveria, ser encarado como um problema exclusivamente epistemológico.

Esse modo particular de colocar-me perante o problema da compartimentalização do saber obrigame, é claro, a dar continuidade a esta minha reflexão, considerando-o do modo como ele está hoje posto à comunidade de prática acadêmico-científica da ANPEd. Vou procurar, porém, focalizar esse problema não em toda a sua abrangência, mas atendo-me sobretudo ao caso particular da situação do GT de Educação Matemática relativamente aos demais GTs que compõem a área mais abrangente da educação no espaço institucional da ANPEd, sem a menor pretensão de estar representando aqui um improvável ponto de vista político-epistemológico unitário de uma suposta comunidade político-epistemologicamente uniforme de educadores matemáticos.

Tendo como referência a situação concreta, específica e irredutível da comunidade de prática científico-acadêmica da ANPEd, vou procurar argumentar em favor do ponto de vista de que a educação matemática deveria manter sua autonomia em relação aos demais grupos de trabalho atualmente reconhecidos pela ANPEd, mas não em relação à própria área da educação. Isso significa, em primeiro lugar, que, embora a comunidade de educadores matemáticos possa participar e atuar, enquanto comunidade global ou subcomunidades, de vários espaços, sociedades e eventos científicos, quando nos voltamos ao trabalho específico e bem definido de pensar e fazer educação matemática concebida como prática de investigação acadêmica a nossa comunidade mais ampla de referência e atuação deveria ser a ANPEd, e não as Sociedades Brasileiras de Matemática Pura ou Aplicada, a Sociedade Brasileira de História da Matemática ou mesmo a Sociedade Brasileira de Educação Matemática, dado que esta última sociedade de forma alguma se reduz ou tem a intenção de se reduzir a uma sociedade brasileira de pesquisadores em educação matemática.

Usando termos de Wittgenstein, no mundo contemporâneo é possível fazer a matemática participar de muitos jogos de linguagem irredutíveis, associados a diferentes formas de vida que mantêm entre si não mais do que semelhanças de família. Poderíamos, portanto, ver a matemática como: uma disciplina escolar; uma disciplina acadêmica; um campo de profissionalização e, portanto, uma área de atuação profissional; uma linguagem para outras ciências; uma ideologia; uma tecnologia simbólica; uma atividade lúdica; um conjunto de conhecimentos historicamente acumulados; um campo autônomo de investigação acadêmico-científica; um campo referencial sobre o qual se pode fazer incidir investigações acadêmicocientíficas de naturezas diversas, como, por exemplo, quando a matemática se constitui em campo de investigação filosófica, histórica, sociológica, antropológica ou psicológica etc. Podemos ainda ver a matemática como um conjunto de práticas socioculturais singulares realizadas por diferentes comunidades de prática como comunidades indígenas, náuticas, comerciais, financeiras, de vendedores ambulantes, de astrônomos, de costureiras, de ceramistas, de artistas etc.

É claro que não é apenas a matemática que poderia ser vista dessa forma multidimensional; de certo 
modo, e com algumas variações, o mesmo poderia ser dito em relação à educação em geral e à educação matemática em particular. Pensamos, porém, que, para a consideração do caso situado, específico e irredutível da ANPEd, a educação matemática só nos interessa ser vista como prática de investigação acadêmicocientífica; e, mesmo que nos possa interessar que seja vista também de outras formas, deveríamos olhá-la por essas outras formas com os olhos do investigador acadêmico.

É esse, a meu ver, um dos principais critérios que poderiam dar legitimidade à proposta de manutenção da educação matemática como um GT da ANPEd. Tal legitimidade não se assenta no fato de a educação matemática poder ou não ser vista como uma disciplina escolar, ou mesmo como disciplina acadêmica ou como outra coisa qualquer, mas sim no fato de ela constituir, em nossos dias, um campo de investigação acadêmica institucionalmente enraizada, em nível nacional como internacional, congregando em torno de seu objeto de investigação uma comunidade de prática científico-acadêmica relativamente ampla, produtiva, organizada, que tem como propósito comum a promoção da pesquisa em torno desse objeto.

Mais propriamente do que um parâmetro epistemológico, entendo ser esse um argumento sociológico, uma vez que está baseado nas principais características que definem a identidade social de uma comunidade de prática científico-acadêmica, bem como nas características do processo de institucionalização da pesquisa acadêmica em nosso país e no mundo contemporâneo.

Mesmo que os integrantes da comunidade de educadores matemáticos vissem a matemática exclusivamente como uma disciplina escolar - visão estreita essa que não retrata, de modo algum, o que se passa hoje no interior dessa comunidade - haveria, portanto, para dar apenas um exemplo, uma diferença significativa entre vivenciar a matemática como disciplina escolar, isto é, atuar como um professor de matemática da educação básica, e investigá-la academicamente como disciplina escolar, isto é, atuar como um pesquisador em educação, na linha de pesquisa que toma como objeto de investigação as disciplinas escolares.

Além disso, investigá-la como disciplina escolar poderia abrir um leque de opções que faria a educação matemática aproximar-se de alguns e a afastar-se de outros dos grupos de trabalho da ANPEd. Poderíamos, por exemplo, centrar as nossas investigações no problema do currículo escolar de matemática, e essa opção faria a educação matemática aproximar-se do GT Currículo, por afinidade temática relativa ao objeto de estudo. Poderíamos, em uma segunda opção, centrar as nossas investigações no problema da história escolar da educação matemática, e isso a levaria a estabelecer uma conexão com o GT História da Educação, agora por afinidade em termos de forma de abordagem do objeto de estudo. Poderíamos também, em uma terceira opção, centrar nossas investigações no problema das diferentes perspectivas político-epistemológicas, sociológicas, psicológicas, antropológicas, ideológicas e didáticas que vêm orientando a educação matemática escolar no mundo contemporâneo, o que levaria a educação matemática a conectar-se com os GTs Filosofia da Educação, Sociologia da Educação, Psicologia da Educação, Didática. Poderíamos continuar explicitando outras opções, mas as apresentadas já bastam para entender a natureza desse meu argumento.

Argumento que abre à comunidade de pesquisadores em educação matemática pelo menos duas possibilidades de inserção dentro da comunidade mais ampla de pesquisadores em educação da ANPEd: uma primeira seria a continuidade no investimento de esforços no sentido de manutenção de um GT de Educação Matemática em relação aos demais GTs da ANPEd; uma segunda seria a dissolução do GT autônomo e a dispersão da microcomunidade que o integra nas demais microcomunidades que constituem cada um dos demais GTs institucionalizados pela ANPEd.

Tendo a posicionar-me favoravelmente à primeira alternativa, isto é, à manutenção das identidades de nossa e das demais microcomunidades de pesquisadores em educação, identidades essas que só se constituíram e se constituem com base na delimita- 
ção e consideração comum de um mesmo objeto de investigação.

Ainda que, por essa ou aquela razão, a dispersão dos membros da comunidade de pesquisadores em educação matemática pelos demais GTs da ANPEd não tenha o poder de destruir ou ameaçar a identidade dessa comunidade em outras situações concretas em que ela também se constitui como comunidade, penso que atualmente, em nosso país, a ANPEd constitui o único espaço político-acadêmico e interinstitucional interativamente amplo no qual diferentes comunidades de pesquisadores em educação, dispersas em diferentes instituições e regiões brasileiras, têm a oportunidade e o direito de participar e atuar autonomamente, ampla e exclusivamente como comunidades de pesquisadores nos diferentes objetos específicos de investigação por elas constituídos.

Alguns poderiam objetar dizendo que certas comunidades de educadores já conseguiram constituir outros espaços interinstitucionais que possibilitariam esse mesmo tipo de inserção e interação mais restritas, em termos de pesquisa, que a ANPEd oferece. E esse seria justamente o caso que se apresenta para o GT de Educação Matemática. Mas estariam na mesma condição o GT de História da Educação, o GT de Didática, o GT de Psicologia da Educação e quase todos - senão todos - os demais GTs da ANPEd. Não consigo ver, entretanto, em que sentido o movimento organizado e independente de cada uma dessas microcomunidades no sentido de abrir novos canais ou fóruns de interação e debate em torno de seus objetos poderia constituir um contra-argumento sólido à possibilidade de organização autônoma dessas mesmas microcomunidades no interior da ANPEd.

Não consigo também perceber alguma solidez no contra-argumento que se costuma levantar, de que a constituição autônoma dessas microcomunidades de pesquisadores no interior da ANPEd poderia dificultar - ou mesmo inviabilizar - o diálogo entre elas, uma vez que um tal tipo de contra-argumento valeria para todas as microcomunidades, não tendo, desse modo, o poder de operar sobre uma mais do que sobre as outras.
Entretanto, parece que, quando consideramos o caso do GT de Educação Matemática, esse contraargumento coloca-se de forma mais contundente. E muitos atribuem isso ao fato de ser o nosso GT o único dito disciplinar específico, e, tendo ele tal característica singular em relação aos demais, acabaria tornandose impermeável ao diálogo com os demais GTs.

Acredito que esse segundo contra-argumento mereça uma consideração mais detalhada, tendo em vista que ele tem sido amplamente utilizado por parte considerável da comunidade de educadores em geral e por integrantes da própria comunidade de educadores matemáticos.

Mas a amplitude do uso desse segundo contraargumento não lhe garante, a nosso ver, maior solidez. Em primeiro lugar, porque geralmente tal contra-argumento vem acompanhado de certo preconceito injustificável em relação à eleição do tema da disciplinaridade escolar específica como objeto legítimo e relevante de pesquisa educacional, e quase nunca vem igualmente acompanhado das razões pelas quais a disciplinaridade escolar específica deveria ser desvalorizada enquanto objeto de investigação educacional.

Um pressuposto no qual muitas vezes essa desvalorização se ancora é aquele que estabelece uma relação causal entre a defesa da legitimidade e relevância de pesquisas envolvendo disciplinas escolares específicas e a defesa da manutenção da estrutura disciplinar hoje posta, ou que possa vir a ser posta no âmbito do currículo escolar em quaisquer níveis. Penso, entretanto, que uma coisa nada tem a ver, necessariamente, com a outra. Ao contrário, acredito que pesquisas envolvendo disciplinas escolares específicas poderiam contribuir e trazer mais sólidos e originais pontos de vista em favor da inter, multi, ou mesmo, não-disciplinarização do currículo escolar. De qualquer modo, não é a pesquisa disciplinar que teria o desejo ou mesmo o poder de, por si só, reforçar ou alterar a estrutura da organização curricular atualmente em vigor nas escolas e universidades, embora ela possa e deva, a meu ver, contribuir para a promoção e problematização desse debate. 
Um segundo pressuposto em que, muitas vezes, se ancora esse contra-argumento de que a pesquisa relativa a campos disciplinares específicos impediria o diálogo é o da subordinação explícita ou tácita do particular ao geral, em todos os domínios e situações concretas em que tal relação costuma operar, o que gera a crença abusiva - para não dizer completamente equivocada e discriminadora - de que é sempre o geral que esclarece o particular ao qual se vincula, cabendo portanto ao particular aprender com o geral, mas nunca o geral com o particular. Sendo a educação matemática, vista ou não como disciplina escolar, sempre um particular em relação a todas as primeiras instâncias do geral constituídas pelos demais GTs da ANPEd, bem como em relação a uma segunda instância do geral denominada educação, então não nos restaria outra alternativa senão a de suportar obedientemente o peso desse não questionado imperialismo epistemológico do geral sobre o particular, o qual quase sempre vem acompanhado de um esquema valorativo de inferiorização do particular em relação ao geral ao qual se vincula.

Hoje, nós, educadores matemáticos, sabemos muito bem os resultados desastrosos produzidos pela aplicação desse princípio de subordinação do particular ao geral, ao nível da educação escolar, na época em que estávamos sob a influência do ideário do Movimento da Matemática Moderna. Acreditavase, com base em tal princípio e numa suposta unidade interna entre todos os campos da matemática, que se a criança aprendesse a lidar com as chamadas estruturas matemáticas em seus níveis mais genéricos e abstratos, ela seria também capaz de transferir e aplicar esses conhecimentos a todos os casos particulares em que eles viessem a intervir.

Mas, se hoje em dia se tornou difícil defender e caracterizar o que seria essa tal unidade dentro da própria matemática, por que deveríamos insistir em acreditar e defender uma suposta unidade do conhecimento em geral? Além disso, se as pesquisas mais recentes em educação matemática têm cada vez mais questionado a noção de transferência automática de conhecimentos de uma situação contextual a outra e posto em relevo a noção de aprendizagem situada, por que deveríamos insistir em defender a existência de uma matemática geral, abstrata, universal e desrreferencializada que se aplicaria sem problemas ou resistências a todas as situações particulares?

Tendo em vista que a tensão entre o geral e o particular tem assumido conotações político-ideológicas diversas no interior de quase todos os domínios das ciências sociais contemporâneas, com claros reflexos sobre a polêmica relativa ao direito às diferenças, e tendo ainda presente que o imperialismo epistemológico do geral em relação ao particular encontra-se hoje fortemente abalado nos domínios da própria matemática e da educação matemática, por que razão deveríamos recorrer a ele como um argumento que tivesse o poder de justificar a impossibilidade do diálogo entre os integrantes das diferentes microcomunidades autônomas da ANPEd, constituídas ou não com base no critério do disciplinar específico? Já que todas essas microcomunidades constituíram sua identidade acadêmico-científica com base em alguma temática específica - escolar ou não, disciplinar ou não -, não seria mais proveitoso que todas elas se abrissem ao diálogo umas com as outras, respeitando-se em suas diferenças e aprendendo com elas, em vez de hierarquizá-las de acordo com critérios discriminatórios questionáveis?

Gostaria finalmente de considerar aqui o argumento - utilizado por muitos matemáticos, educadores e mesmo educadores matemáticos - de que, dependendo dos modos como são concebidos os objetos de investigação nos domínios da matemática e da educação, a prática de investigação em educação matemática seria mais bem situada fora do domínio da prática investigativa em educação.

É importante considerar aqui tal argumento, uma vez que a própria comunidade de pesquisadores em educação matemática parece continuar dividida - por razões de ordem corporativa ou de fato epistemológica - em relação à questão da legitimidade epistemológica de ter-se delegado a avaliação institucional de certos programas de pós-graduação em educação matemática a um comitê independente e autônomo, 
cuja composição diminui consideravelmente o poder de interferência da área de educação em geral sobre esse processo avaliativo, ao mesmo tempo em que aumenta consideravelmente o poder da área de matemática e de áreas das ciências naturais como a física, a química e a biologia.

É claro que, discordando por princípio éticopolítico pessoal de quaisquer critérios de natureza corporativa que poderiam ser alegados para a defesa de um tal argumento, vou explicitar aqui apenas razões e convicções de natureza propriamente epistemológica para sua rejeição.

Sabemos que, na história, muitas práticas envolvendo matemática mantiveram diálogo constante e produtivo com as ciências naturais, notadamente com a física. Por essa razão, no plano da educação escolar, seria não só desejável como também produtivo continuar esse diálogo por meio da realização de práticas que aproximem ou mesmo eliminem barreiras entre a matemática e as disciplinas científicas em geral, bem como entre a matemática e a educação artística e literária.

Porém, quando consideramos a educação matemática como prática de investigação acadêmica, mesmo mantendo uma atitude multidisciplinar ou não-disciplinar relativamente à educação escolar, os campos com os quais mantemos diálogo geralmente não são os das ciências naturais. Poderíamos colocar aqui o desafio de fazer um levantamento das referências bibliográficas das dissertações de mestrado e teses de doutorado em educação matemática, bem como em educação em ciências, produzidas ou não em nosso país, com o objetivo de fazer uma espécie de hit parade dos autores mais citados com os quais os pesquisadores desses dois terrenos procuram estabelecer diálogos para constituir os referenciais metodológico-conceituais de seus trabalhos.

Penso que a conclusão a que chegaríamos seria a de que os autores mais citados, tanto pelos pesquisadores em educação matemática quanto pelos pesquisadores em educação em ciências, não pertenceriam a campos das ciências duras, como a física, a química, a biologia ou mesmo a matemática. Ao contrário, constataríamos não só que os pesquisadores em educação matemática e em educação em ciências dialogam com autores comuns filiados a diferentes campos das ciências sociais como a história, a filosofia, a sociologia, a antropologia, a psicologia, a pedagogia, a lingüística, a semiótica etc. como também que seriam esses os autores que constituiriam o campo de diálogo dos pesquisadores em educação em geral. Se assim é, por que continuar insistindo no argumento de que deveríamos criar uma instância composta de campos disciplinares específicos das ciências da natureza, à qual seria delegado o poder institucional de avaliar e tomar decisões acerca de programas de pós-graduação e outros projetos relativos à educação matemática e à educação em ciências?

Alguns poderiam ainda objetar alegando fazer sentido uma aproximação epistemológica da matemática com as ciências naturais. Sinceramente, não acho nada natural essa aproximação. Ela só continua o sendo para aqueles que, saudosistas do século XIX, quer do empirismo indutivista de John Stuart Mill, quer do positivismo comteano, ainda acreditam ser a matemática a mais geral das ciências naturais, ou então, para aqueles que, ainda fascinados pelo quase-empirismo lakatosiano, ainda acreditam ser os resultados da matemática falíveis e eternamente abertos à crítica.

É claro que seria inútil tentar buscar uma concepção consensual e universal que tivesse a força e o poder de contemplar todos os significados associados às diferentes formas de mobilizar a palavra "matemática" ou às diferentes maneiras de mobilizar cultura matemática. Isso porque tal suposta concepção não teria um valor de uso ou um significado operatório efetivo para qualquer comunidade que se veja envolvida com matemática para a realização de suas atividades.

Talvez tenha sido por essa razão que Wittgenstein (2000, p. 228), diante da questão "O que é a matemática?", preferiu respondê-la de forma interrogativa, nãoessencialista e generosa: "Por que eu não deveria dizer que o que chamamos de matemática é uma família de atividades com uma família de propósitos?". 
É claro que tal resposta - que nos autoriza a falar em matemáticas no plural bem como a ver cada uma dessas matemáticas não mais como um conjunto de resultados ou conhecimentos fixos e universais, mas como um conjunto de atividades ou práticas sociais -é mesmo assim de tamanha generosidade que reclama por pelo menos mais um lance delimitador.

Wittgenstein busca tal lance delimitador não mais em uma suposta natureza comum ou propriedades inalienáveis dos objetos sobre os quais a atividade matemática poderia incidir nem em uma suposta natureza comum ou propriedades inalienáveis das próprias ações que poderiam incidir sobre tais objetos ou das relações que poderíamos estabelecer entre eles, mas nas significações singulares e intransferíveis das normas socialmente convencionadas e legitimadas por diferentes comunidades de prática e que orientam inequivocamente a realização dessas atividades por parte dos seus membros.

Desse modo, a atividade matemática pode incidir sobre quaisquer objetos com base em quaisquer propósitos, e o que caracteriza tal atividade, bem como as suas produções como sendo propriamente matemáticas, seria o fato de ela constituir-se como atividade normativa indicadora não de uma única significação, mas de significações que se tornaram inequívocas $e$ incontroversas para os membros de uma determinada comunidade, depois de terem passado por um período de negociação social interna aparadora de divergências semânticas.

Inspirado pelo pensamento do segundo Wittgenstein, estou aqui sugerindo uma concepção de matemática que se caracteriza por ser antiplatônica, antiempirista; antiindutivista; antiintuicionista; antiestruturalista e antiessencialista. Trata-se de uma forma particular de conceber a matemática que, em virtude de seu caráter lingüístico-semântico, aproxima-a das ciências das linguagens; que, em virtude de seu caráter normativo, aproxima-a das ciências jurídicas; que, em virtude da natureza e da origem social das normas orientadoras dessa atividade, aproxima-a da sociologia; e que, em virtude do caráter não universal e polissêmico atribuído a tais normas por diferentes comunidades de prática que as constituem e utilizam, aproxima-a da antropologia.

Como se pode perceber, não estou fazendo qualquer aproximação do campo epistemológico das matemáticas ao das chamadas ciências da natureza ou mesmo ao das chamadas ciências exatas, cuja preocupação fundamental incide sobre o estabelecimento de leis quantitativas ou estocásticas. Prefiro, em vez disso, aproximá-las do campo epistemológico de determinadas ciências sociais.

Mas, dado ser o caráter normativo das práticas que envolvem a matemática o elemento que as distinguiria tanto das práticas que envolvem as ciências naturais quanto daquelas que envolvem as humanidades, pensamos que as ciências jurídicas constituiriam o melhor campo epistemológico para a alocação das matemáticas.

Piaget, no seu instigante estudo denominado $A s i$ tuação das ciências do homem no sistema das ciências, distingue do seguinte modo o campo epistemológico das ciências jurídicas em relação àquele das ciências nomotéticas:

\footnotetext{
[...] as ciências jurídicas ocupam uma posição bastante diferenciada pelo fato de o direito constituir um sistema de normas e de uma norma se distinguir, no seu próprio princípio, das relações mais ou menos gerais buscadas, sob a designação de "leis", pelas ciências nomotéticas. Uma norma não provém, com efeito, da simples verificação de relações existentes, mas de uma categoria à parte, que é a do “dever ser”. Assim, é próprio de uma norma prescrever um certo número de obrigações e de atribuições que permanecem válidas mesmo se o sujeito as viola ou não faz uso delas, enquanto uma lei natural assenta num determinismo causal ou numa distribuição estocástica e o seu valor real advém exclusivamente do seu acordo com os fatos. (Piaget, 1970, p. 26)
}

Ainda que o próprio Piaget, em razão de sua concepção estruturalista das matemáticas, não as situasse no campo epistemológico das ciências jurídicas, pensamos que estamos ambos bastante afastados das concepções empiristas clássicas ou contemporâneas da matemática. 
Gauss, na passagem do século XVIII para o século XIX, ainda podia ter alguma razão em ter eleito a matemática a "rainha das ciências". No final do século XIX, após ter ela abdicado o trono e proclamado a República, guardou no baú o cetro, a coroa e as desgastadas pretensões de manutenção hereditária do poder. Com Wittgenstein, ela desejou convidar todas as suas incontáveis irmãs a passear pelas ruas com vestes comuns, ao lado de práticas e pessoas comuns, e a conversar com elas em linguagem comum. Ainda que muitos tentem convencê-las a restaurar a Monarquia, as irmãs, de mãos dadas, continuam a caminhar convictas em direção a uma nova República, na qual todos possam ocupar um lugar e constituir a sua identidade.

\section{Referências bibliográficas}

KEDROV, Boniface M. Classificación de las ciências. Tomo I. Madrid: Editorial Progreso y Editorial Ciências Sociales, 1974.
MORIN, Edgar. O método: o conhecimento do conhecimento. Porto Alegre: Sulina, 1999.

PIAGET, Jean. A situação das ciências do homem no sistema das ciências. Lisboa: Livraria Bertrand, 1970.

RORTY, Richard. Contra a unidade. Folha de S.Paulo, Caderno Mais, p. 7-8, 22 mar. 1998.

WILSON, Edward O. A unidade do conhecimento: consiliência. Rio de Janeiro: Campus, 1999.

WITTGENSTEIN, Ludwig. Cultura e valor. Lisboa: Edições 70, 2000.

ANTONIO MIGUEL, mestre e doutor em educação pela Universidade Estadual de Campinas (UNICAMP), é professor assistente do Departamento de Ensino e Práticas Culturais da Faculdade de Educação e coordenador do grupo de pesquisa "História, Filosofia e Educação Matemática” (HIFEM) da Faculdade de Educação da mesma universidade.E-mail:miguel@unicamp.br

Recebido em agosto de 2007 Aprovado em abril de 2008 
Antonio Miguel

\section{Áreas e subáreas do conhecimento, vínculos epistemológicos: o GT de Educação Matemática da ANPEd}

Neste artigo temos como propósito discutir a questão da compartimentalização do conhecimento, considerando-a tanto em sua dimensão epistemológica mais ampla quanto no modo como ela se apresenta hoje à comunidade de prática acadêmico-científica da ANPEd. Nessa segunda dimensão, damos destaque ao caso particular da situação do Grupo de Trabalho de Educação Matemática relativamente aos demais grupos de trabalho já institucionalizados pela ANPEd no âmbito da pesquisa brasileira na área de educação.

Palavras-chave: compartimentalização do conhecimento; grupos de trabalho da ANPEd; Grupo de Trabalho de Educação Matemática

\section{Areas and sub-areas of knowledge} and their epistemological links: ANPEd's working group in mathematics education In this article, our purpose is to discuss the question of knowledge compartmentalization considering it both in its wider epistemological dimension as in the way it presents itself, nowadays, to the ANPEd community of academic-scientific practice. In that more restricted aspect, we stress, particularly, the situation of the mathematics education working group in relation to the other working groups already institutionalized by ANPEd in the field of Brazilian educational research.

Key words: knowledge compartmentalization; ANPEd's working groups; working group in mathematics education

Áreas y subáreas del conocimiento, vínculos epistemológicos: o GT de la Educación Matemáticas de ANPEd

En este artículo, es nuestro propósito discutir la cuestión de la compartimentalización del conocimiento, considerándola tanto en su dimensión epistemológica más amplia en cuanto al modo como ella se presenta hoy a la comunidad de práctica académico científica de ANPEd. En esta segunda dimensión, destacamos el caso particular de la situación del grupo de Educación Matemáticas relativamente a los demás grupos de trabajo ya institucionalizados por ANPEd en el ámbito de la pesquisa brasileña en el área de educación. Plabras clave: compartimentalización del conocimiento; grupos de trabajo de ANPEd; Grupo de Trabajo de Educación Matemáticas 